\title{
Differences in prostate cancer detection between Canadian and Saudi populations
}

\author{
O.Z. Al-Abdin ${ }^{1,2,3}$, D.M. Rabah ${ }^{1,2}$, G. Badr ${ }^{1,4}$, A. Kotb ${ }^{1}$ and A. Aprikian ${ }^{3}$ \\ ${ }^{1}$ Princess Al-Johara Al-Ibrahim Center for Cancer Research, Prostate Cancer Research Chair, \\ College of Medicine, King Saud University, Riyadh, Saudi Arabia \\ ${ }^{2}$ Department of Urology/Surgery, College of Medicine, King Saud University, Riyadh, Saudi Arabia \\ ${ }^{3}$ Department of Urology, McGill University Health Centre, Montreal, Quebec, Canada \\ ${ }^{4}$ Zoology Department, Faculty of Science, Assiut University, Assiut, Egypt
}

\begin{abstract}
Few studies have addressed racial differences in prostate cancer (PCa) detection between Western and Arabian countries, although PCa has a significantly lower prevalence in Arabic populations compared to Western populations. Therefore, an explanation of this difference is lacking. Serum prostate-specific antigen (PSA) is a valuable marker used to select patients who should undergo prostate biopsies, although the manner in which it is used may require adjustments based on the ethnic population in question. We investigated racial differences in the PCa detection rate between Canadian and Saudi populations. A retrospective analysis was performed of data collected prospectively over 5 consecutive years in urology clinics at the McGill University Health Center (MUHC) and King Saud University Hospital (KSUH). Men who had high ( $>4 \mathrm{ng} / \mathrm{mL})$ or rising PSA levels and a negative digital rectal examination were eligible. A total of 1403 Canadian and 414 Saudi patients were evaluated for the study; 717 and 158 men, median age 64 and 68 years, were included in the MUHC and KSUH cohorts, respectively, $\mathrm{P}<0.0001$ ). Median serum PSA, prostate volume, and PSA density values were $6.1 \mathrm{ng} / \mathrm{mL}, 47.3 \mathrm{~g}$, and $0.12 \mathrm{ng} \cdot \mathrm{mL}^{-1} \cdot \mathrm{g}^{-1}$, respectively, for MUHC patients and $5.2 \mathrm{ng} / \mathrm{mL}, 64.5 \mathrm{~g}$, and $0.08 \mathrm{ng} \cdot \mathrm{mL}^{-1} \cdot \mathrm{g}^{-1}$, respectively, for KSUH patients $(P<0.0001$, t-test followed by one-way ANOVA). In addition, the KSUH group had a significantly lower PCa detection rate among patients younger than 60 years of age and with PSA values $<10 \mathrm{ng} / \mathrm{mL}$.
\end{abstract}

Key words: Prostate cancer; Serum; PSA; PSA density; Digital rectal examination

\section{Introduction}

Prostate cancer is a common health problem that begins to develop in men at 50 years of age and reaches its peak at 70 years of age in the majority of cases. Variations in the incidence and prevalence of prostate cancer exists among Western, Asian, and Arabic populations. The highest incidence of this disease is in the United States and Canada followed by European countries, whereas the incidence is lower in Asian populations and lowest in Arabic populations $(1,2)$. While the incidence of prostate cancer was reported to be approximately 100 to 127 per 100,000 men in the United States (3), this rate was as low as $3.1,3.3$, and 6.5 per 100,000 men in Saudi Arabia (4), Oman (5), and Kuwait (6), respectively. This marked difference in the prostate cancer incidence and prevalence between Western and Arabic countries is interesting, and many researchers have attempted to discover potential explanations for this dissimilarity.
One theory for this difference in prostate cancer prevalence is male circumcision, which is practiced in most Arabic countries as a religious obligatory act related to Islam and is performed during the first months of an infant's life. Morris (7) reported that male circumcision serves as a surgical vaccine that protects against genital and urinary bacterial and viral infections and protects against penile and prostate cancer. In a study of 20,243 men in Finland, HPV-18 infection was associated with a 2.6 -fold increase in the prostate cancer risk $(\mathrm{P}<0.005)$ (8); similarly, there was a 2.4-fold increased risk for HPV16 infection. These findings are also similar to data showing increased levels of penile HPV infection in uncircumcised men (9). Many investigators have linked HPV infection to the etiology and progression of prostate cancer $(8,10)$, and some studies have reported that uncircumcised men have more than twice the prostate cancer incidence as those who are circumcised $(11,12)$,

Correspondence: G. Badr, Princess Al-Johara Al-Ibrahim Center for Cancer Research, Prostate Cancer Research Chair, College of Medicine, King Saud University, P.O. Box 7805, Riyadh 11472, Saudi Arabia. Fax: +966-1467-9781. E-mail: badr73@yahoo.com 
which may explain why prostate cancer is relatively rare among Jewish men.

Another theory for the difference in prostate cancer prevalence between populations is related to environmental factors and dietary habits. For example, it was demonstrated that the age-standardized prostate cancer incidence rate is lower in Asian countries than in the United States and European countries, although the incidence rate for Asians living in the United States is substantially higher than that of those living in their homelands (13). In addition, migration studies (14) have reported an increase in prostate cancer incidence among Asian men after emigration to the United States. Similarly, a study from Egypt (15) confirmed higher vegetable intake as a significant factor for prostate cancer risk reduction, and a systematic review (16) confirmed that a diet low in fat and meats but rich in vegetables and fruits is recommended for reducing prostate cancer risk. In contrast, a study of Arab Americans living in the Detroit metropolitan area, which was identified by a MEDLINE search for cancer risk in Arab Americans, concluded that Arab Americans possess similar cancer patterns as those in their home country, which is contrary to the previously mentioned migration studies (17).

A third theory for the difference in prostate cancer prevalence involves racial differences in the serum testosterone level during adulthood. Kehinde et al. (18) studied differences in the serum testosterone levels of Arab and German patients with diseases other than prostate cancer and demonstrated a significantly lower testosterone level in the middle age group from the Arab population ( $<30$ years), suggesting that the relatively lower serum testosterone level in that age group may be protective in the long run. This theory is based on findings in Kuwait and Oman, but it remains to be determined whether these findings are applicable to all Arabic populations. In addition, a recent study of Emirati Arabs demonstrated that Emirati men have normal serum testosterone levels that may be well maintained in older age groups and that this maintenance was attributable to innate ethnic characteristics (19). A Jordanian study (20) also detected a higher mean serum prostate-specific antigen (PSA) level in all age groups examined, suggesting that Jordanian men maintain a reasonably stable testosterone level throughout life. According to the study by Catalona et al. (21), the serum testosterone level has a significant effect on the total PSA level; however, it remains unclear whether higher serum testosterone levels are associated with higher prostate cancer risk. While some studies demonstrated direct associations (22), others failed to document an association between serum testosterone level and prostate cancer risk (23).

The current study was designed to investigate racial differences in prostate cancer detection rates between Canadian and Saudi populations and to investigate racial differences in the use of age and prostate volume adjusted serum PSA level as indirect markers of circulating androgens between ethnic groups.

\section{Patients and Methods}

Data were collected from patients examined at McGill University Health Centre (MUHC) and King Saud University Hospital (KSUH) over 5 consecutive years for prostate cancer detection. The inclusion criteria selected men who received a trans-rectal ultrasound (TRUS)guided prostatic biopsy due to a single high serum PSA level (PSA $\geq 4 \mathrm{ng} / \mathrm{mL}$ ), or a rising serum PSA level upon repeated measurements, and the absence of a suspicious mass on digital rectal examination. All aspects of this study were approved by the ethics committees of MUHC and $\mathrm{KSUH}$, and all patients provided written informed consent according to the Declaration of Helsinki.

Based on the above criteria, 717 and 158 men from the MUHC and $\mathrm{KSUH}$, respectively, were included in the study. The data collected included patient age, serum PSA level, prostate volume, PSA density (PSAd), and the prostatic biopsy result (i.e., cancer vs no cancer). Prostate volume was measured in both groups using a prolate ellipsoid formula with a TRUS. Prostate biopsies were performed using the current standardized template.

To correlate the age-adjusted serum PSA level, both cohorts were divided into four age groups: <50, 50-59, $60-69$, and $\geq 70$ years. To correlate prostate volume and cancer rate with the serum PSA level, both cohorts were divided into three groups according to serum PSA level: $<4,4$ to $<10$, and $\geq 10 \mathrm{ng} / \mathrm{mL}$. To study racial differences in the level of PSA secretion from the prostate, we combined all the cases into a single cohort and calculated the 25th, 50th, and 75th percentiles of prostate volume. Both racial cohorts were then correlated with regard to the resulting prostate volume percentiles.

\section{Statistical analyses}

Statistical analyses were performed using the Fischer exact test, Student $t$-test, one-way analysis of variance (ANOVA), and Mann-Whitney U-test. A MEDLINE database search of all English language publications concerning prostate cancer risk and serum PSA level in Arabic and Western populations was performed.

\section{Results}

The median age of the MUHC and KSUH groups was 64 and 68 years, respectively $(P<0.02)$. The median serum PSA level and PSAd were significantly higher in the MUHC group, whereas prostate volume was significantly greater in the KSUH group. Table 1 illustrates the differences between cohorts.

In each group, increasing patient age was associated with a trend towards increasing levels of serum PSA and PSAd, although this association was not statistically 
Table 1. Median values for the MUHC and KSUH groups.

\begin{tabular}{lcc}
\hline & MUHC & KSUH \\
\hline Number of patients & $717^{*}$ & $158^{\star}$ \\
Age (years) & $64^{+}$ & $68^{+}$ \\
Median serum PSA $(\mathrm{ng} / \mathrm{mL})$ & $6.1^{\#}$ & $5.2^{\#}$ \\
Median prostate volume $(\mathrm{g})$ & $47.3^{\#}$ & $64.5^{\#}$ \\
Median PSAd $\left(\mathrm{ng} \cdot \mathrm{mL}^{-1} \cdot \mathrm{g}^{-1}\right)$ & $0.12^{\#}$ & $0.08^{\#}$ \\
Cancer & & \\
$\quad$ No & 366 & 136 \\
Yes & $351(49 \%)$ & $22(14 \%)$ \\
\hline
\end{tabular}

Data are reported as median values. MUHC: McGill University Health Center. KSUH: King Saud University Hospital. PSA: prostate-specific antigen. PSAd: PSA density. ${ }^{*} P=0.0001$, ${ }^{+} \mathrm{P}=0.02,{ }^{\#} \mathrm{P}<0.0001, t$-test followed by one-way ANOVA.

significant. Table 2 reports the results of an ANOVA performed for the age-adjusted clinical variables of each group separately and a $t$-test for comparison between groups.

By correlating patient age with the incidence of detecting cancer upon prostatic biopsy in the MUHC group, increasing patient age was significantly associated with a higher incidence of detecting cancer upon prostatic biopsy. In addition, although increasing patient age was also associated with a higher incidence of detecting prostate cancer in the KSUH group, it was not statistically

Table 2. Age-associated changes in PSA level, prostate volume, and PSAd in the MUHC and KSUH groups.

\begin{tabular}{llll}
\hline Age (years) & MUHC & KSUH & $P$ \\
\hline PSA (ng/mL) & & & \\
$\quad<50$ & 7 & 6.4 & 0.7 \\
$50-59$ & 7 & 4.4 & 0.007 \\
$60-69$ & 7.6 & 59 & $<0.0001$ \\
$\geq 70$ & 7.2 & 35 & 0.008 \\
P & 0.7 & 0.2 & \\
Prostate volume $(\mathrm{g})$ & & & \\
$<50$ & 64 & 61.6 & 0.8 \\
$50-59$ & 56 & 59 & 0.7 \\
$60-69$ & 54 & 72 & 0.001 \\
$\geq 70$ & 55 & 79 & $<0.001$ \\
P & 0.1 & 0.2 & \\
PSAd $\left(\mathrm{ng} \cdot \mathrm{mL}^{-1} \cdot \mathrm{g}^{-1}\right)$ & & & \\
$<50$ & 0.13 & 0.08 & 0.2 \\
$50-59$ & 0.15 & 0.08 & 0.04 \\
$60-69$ & 0.17 & 0.1 & $<0.0001$ \\
$\geq 70$ & 0.16 & 0.28 & 0.04 \\
P & 0.4 & 0.8 & \\
\hline
\end{tabular}

Data are reported as median values. ANOVA was performed for the age-adjusted clinical variables of each group separately and a $t$-test was used for comparison between groups. See Table 1 legend for explanation of abbreviations. significant. There was also a significantly higher incidence of cancer detection in the MUHC vs KSUH groups in all age groups examined. Table 3 demonstrates the ageadjusted prostate cancer incidence for each group separately as well as the differences between groups.

Cancer incidence correlated with age, prostate volume, and PSAd for the MUHC and KSUH groups separately and collectively for each serum PSA category. Table 4 demonstrates group characteristics with regards to different PSA categories.

We next tested the association between PSAd (using a cut-off value of 0.15 ) and cancer prevalence in the McGill and Saudi groups individually. These correlations are shown in Table 5.

Using the prostate volume 25th, 50th, and 75th percentiles (35.66, 48.15, and $69.23 \mathrm{~g}$, respectively), we compared median serum PSA values between prostate volume and racial groups. The results indicated that PSA secretion was significantly lower in the reduced prostate volume group $(\leq 48.15 \mathrm{~g}$ ) in both the Saudi and McGill cohorts, whereas PSA secretion tended to be similar between ethnic groups among individuals with larger prostates. Table 6 illustrates the relationship between prostate volume percentile, serum PSA level, and cancer detection upon TRUS-guided biopsy.

\section{Discussion}

Serum PSA is a widely used parameter for early prostate cancer detection and monitoring. In Western countries, men with a total PSA $<2.5 \mathrm{ng} / \mathrm{mL}$ have a lower probability of developing prostate cancer, whereas those with a PSA $>10 \mathrm{ng} / \mathrm{mL}$ have a $>50 \%$ chance of developing prostate cancer $(21,24)$. PSAd is another important parameter that was introduced by Benson and colleagues (25) as a useful tool for increasing the specificity of prostate cancer detection. Different PSAd cut-off values, ranging from 0.1 to 0.15 , have been proposed by urologists, with the goal of increasing the specificity of prostate cancer detection for values within the "grey area" of the PSA range and avoiding unnecessary prostatic biopsies (26).

Table 3. Age-associated prevalence of prostate cancer in the MUHC and KSUH groups.

\begin{tabular}{lccc}
\hline Age (years) & MUHC & KSUH & P \\
\hline$<50$ & $17 / 44(38 \%)$ & $0 / 6(0 \%)$ & 0.06 \\
$50-59$ & $161 / 393(41 \%)$ & $2 / 24(8 \%)$ & 0.001 \\
$60-69$ & $397 / 750(53 \%)$ & $9 / 54(16.6 \%)$ & $<0.0001$ \\
$\geq 70$ & $114 / 216(53 \%)$ & $22 / 158(14 \%)$ & $<0.0001$ \\
$\mathrm{P}$ & $<0.0001$ & 0.5 & \\
\hline
\end{tabular}

Data are reported as number with percentages in parentheses. See Table 1 legend for explanation of abbreviations. A $t$-test followed by one-way ANOVA was used for statistical analyses. 
Table 4. Group characteristics with regard to the different PSA categories.

\begin{tabular}{|c|c|c|c|c|c|c|c|}
\hline & \multicolumn{3}{|c|}{ MUHC } & \multicolumn{3}{|c|}{ KSUH } & \multirow[t]{2}{*}{$\mathrm{P}$} \\
\hline & No cancer & Cancer & $\mathrm{P}$ & No Cancer & Cancer & $\mathrm{P}$ & \\
\hline \multicolumn{8}{|l|}{ Whole cohort } \\
\hline Number & 366 & 351 & - & 136 & 22 & - & $<0.0001$ \\
\hline Age (years) & 63 & 65 & $<0.0001$ & 68 & 70 & 0.2 & $<0.0001$ \\
\hline PSA (ng/mL) & 5.7 & 6.9 & $<0.0001$ & 5.1 & 27 & 0.08 & 0.2 \\
\hline Prostate volume $(\mathrm{g})$ & 46 & 49 & 0.1 & 65 & 54 & 0.4 & 0.3 \\
\hline PSAd $\left(\mathrm{ng} \cdot \mathrm{mL}^{-1} \cdot \mathrm{g}^{-1}\right)$ & 0.10 & 0.14 & $<0.0001$ & 0.07 & 0.2 & 0.4 & 0.8 \\
\hline \multicolumn{8}{|l|}{$\mathrm{PSA}<4$} \\
\hline Number & 154 & 80 & - & 46 & 7 & - & 0.003 \\
\hline Age (years) & 64 & 63 & 0.3 & 67 & 72.4 & 0.1 & 0.003 \\
\hline Prostate volume $(\mathrm{g})$ & 45 & 55 & 0.003 & 59 & 50 & 0.6 & 0.7 \\
\hline PSAd $\left(\mathrm{ng} \cdot \mathrm{mL}^{-1} \cdot \mathrm{g}^{-1}\right)$ & 0.05 & 0.05 & 0.7 & 0.03 & 0.01 & 0.09 & 0.01 \\
\hline \multicolumn{8}{|l|}{ PSA $4-<10$} \\
\hline Number & 560 & 444 & - & 52 & 0 & - & $<0.0001$ \\
\hline Age (years) & 61.6 & 63.3 & $<0.001$ & 67 & - & - & - \\
\hline Prostate volume $(\mathrm{g})$ & 56 & 57 & 0.8 & 77 & - & - & - \\
\hline PSAd $\left(\mathrm{ng} \cdot \mathrm{mL}^{-1} \cdot \mathrm{g}^{-1}\right)$ & 0.11 & 0.11 & 0.4 & 0.11 & - & - & - \\
\hline \multicolumn{8}{|l|}{$P S A \geq 10$} \\
\hline Number & 0 & 165 & - & 22 & 10 & - & $<0.0001$ \\
\hline Age (years) & 0 & 64 & - & 74 & 76 & 0.6 & - \\
\hline Prostate volume $(\mathrm{g})$ & 0 & 57 & - & 100 & 65 & 0.02 & - \\
\hline PSAd $\left(\mathrm{ng} \cdot \mathrm{mL}^{-1} \cdot \mathrm{g}^{-1}\right)$ & 0 & 0.4 & - & 0.19 & 6.7 & 0.01 & - \\
\hline
\end{tabular}

Data are reported as median. See Table 1 legend for explanation of abbreviations. A $t$-test followed by one-way ANOVA was used for statistical analyses.

Most of the available studies and recommendations for prostate cancer are based on findings in Western populations, although very few studies have been performed to evaluate racial differences in serum PSA levels. A Korean study (27) that examined 237 healthy men demonstrated that the median serum PSA level was 0.8 and $0.9 \mathrm{ng} / \mathrm{mL}$ for men younger and older than 50 years, respectively. In addition, a study of the Turkish population found the mean serum PSA and PSAd values to be $1.5 \mathrm{ng} / \mathrm{mL}$ and $0.07 \mathrm{ng} \cdot \mathrm{mL}^{-1} \cdot \mathrm{g}^{-1}$, respectively, for men with a mean age of 56 years (28), and an Iranian study (29) of 3758 men $>40$ years of age demonstrated a mean serum PSA level of $1.6 \mathrm{ng} / \mathrm{mL}$. Additionally, a study

Table 5. The association between PSAd and prostate cancer prevalence in the MUHC and KSUH groups.

\begin{tabular}{lccccc}
\hline \multirow{2}{*}{$\begin{array}{l}\text { PSAd } \\
\left(\mathrm{ng} \cdot \mathrm{mL}^{-1} \cdot \mathrm{g}^{-1}\right)\end{array}$} & \multicolumn{2}{c}{ MUHC } & & \multicolumn{2}{c}{$\mathrm{KSUH}$} \\
\cline { 2 - 3 } \cline { 5 - 6 } & No cancer & Cancer & & No cancer & Cancer \\
\hline$<0.15$ & $265^{*}$ & $193^{*}$ & & $69^{+}$ & $5^{+}$ \\
$>0.15$ & 101 & 158 & & 18 & 6 \\
\hline
\end{tabular}

Data are reported as median values. See Table 1 legend for explanation of abbreviations. ${ }^{*} \mathrm{P}<0.0001,{ }^{+} \mathrm{P}=0.01$ ( $t$-test followed by one-way ANOVA). of 396 Arabic men from Kuwait and Oman found a median serum PSA level of $0.4 \mathrm{ng} / \mathrm{mL}$ (30), and a previous Saudi population screening study conducted at the King Fahd Hospital demonstrated mean serum PSA values of 0.8 , $1.3,1.8$, and $2.3 \mathrm{ng} / \mathrm{mL}$ for men $<50,50-60,60-70$, and $>70$ years of age, respectively (31). Because this was a retrospective analysis, the biopsy criteria were subjective, according to physicians' clinical judgment. Thus, some cases had PSA levels below or above $4.0 \mathrm{ng} / \mathrm{mL}$ that probably did not undergo biopsy due to individual clinical interpretation. This was a significant limitation of our study and is inherent to any such retrospective review.

Our study differs from these previous studies because we analyzed cohorts of patients who underwent a TRUS prostatic biopsy. Based on elevated or rising serum PSA levels, it was notable that the serum PSA level was comparable in both racial cohorts among individuals younger than 60 years of age who underwent a biopsy. In older age groups, the serum PSA level and prostate volume were significantly higher in the Saudi group than the Canadian group, which was unexpected.

In agreement with the Catalona concept (21) regarding the significant association between androgens and serum PSA level, Saudi patients who underwent a TRUS biopsy had a serum PSA level comparable to Canadian men who underwent TRUS, although this finding may be 
Table 6. Relationship between prostate volume percentile, median PSA level, and cancer detection in the MUHC and KSUH groups.

\begin{tabular}{|c|c|c|c|c|c|c|}
\hline \multirow[t]{2}{*}{ Prostate volume $(\mathrm{g})$} & \multicolumn{2}{|c|}{ Serum PSA $(\mathrm{ng} / \mathrm{mL})$} & \multirow[t]{2}{*}{$\mathrm{P}$} & \multicolumn{2}{|c|}{ Cancer } & \multirow[t]{2}{*}{$\mathrm{P}$} \\
\hline & MUHC & $\mathrm{KSUH}$ & & MUHC & KSU & \\
\hline$\leq 35.66$ & 5.9 & 2.4 & 0.002 & $169 / 360$ & $2 / 19$ & 0.001 \\
\hline$>35.66-48.15$ & 5.8 & 2.9 & 0.01 & $170 / 362$ & $2 / 16$ & 0.005 \\
\hline$>48.15-69.23$ & 6.3 & 6.3 & 0.7 & $179 / 352$ & $5 / 25$ & 0.002 \\
\hline$>69.23$ & 6.7 & 7.4 & 0.3 & $171 / 328$ & $4 / 48$ & $<0.0001$ \\
\hline
\end{tabular}

See Table 1 legend for explanation of abbreviations. A $t$-test followed by one-way ANOVA was used for statistical analyses.

contradictory to the previously proposed theory of lower serum testosterone levels in Arabic populations as an explanation for the lower prevalence of prostate cancer. In addition, although the serum PSA level was high in the Saudi group, the cancer incidence was significantly lower in Saudi vs Canadian men among all age groups $(0,8$, 16.6 , and $14 \%$ for Saudi men vs 38, 41, 53, and $53 \%$ for Canadian men aged $50,50-59,60-69$, and $\geq 70$ years of age, respectively). In the MUHC group, increasing patient age was also significantly associated with a higher prostate cancer detection incidence upon biopsy, whereas in the KSUH cohort, prostate cancer detection was always significantly lower, and increasing patient age was not associated with a significantly increased prostate cancer detection rate. It was interesting to observe that patients younger than 50 years of age in the KSUH cohort who underwent TRUS biopsy because of high or rising PSA levels (median PSA for that group was $6.4 \mathrm{ng} / \mathrm{mL}$ ) had an incidence of prostate cancer detection of $0 \%$ in contrast to the Canadian cohort. The incidence of prostate cancer detection in the KSUH group, although low for all age groups, tended to be increased for individuals older than 60 years of age, whereas in the MUHC group (and even in the youngest age group, i.e., those younger than 50 years), PSA elevation corresponded to prostate cancer in a large number of cases. Thus, although recommendations suggest that prostate cancer screening should begin at age 50 in Western populations, our study may recommend that screening in Arabic populations could safely begin at age 60 . The median PSA level for the KSUH group was 59 and $35 \mathrm{ng} / \mathrm{mL}$ for patients $60-69$ and $\geq 70$ years old, respectively, and this was significantly higher than that observed in the MUHC group. However, the incidence of detecting cancer using TRUS-guided biopsy was significantly lower, and the median value was $14 \%$ for all age groups combined, which may suggest the need to raise the recommended PSA value guiding the administration of prostatic biopsy in Arabic populations. This finding may also explain the significantly larger prostate volume in the KSUH group for patients $>60$ years old and may suggest that benign prostatic hyperplasia $(\mathrm{BPH})$ could explain the rise in serum PSA levels. Kehinde et al. (32) studied 160 Arabic men who underwent a TRUS-guided biopsy with a serum PSA level
$>10 \mathrm{ng} / \mathrm{mL}$, and these authors found that the incidence of cancer detection was $11 \%$, which is close to our value, whereas the incidence of $\mathrm{BPH}$ and/or prostatitis was detected in the majority of cases. As a result, these previous authors concluded that a PSA $>10 \mathrm{ng} / \mathrm{mL}$ tends to be caused by BPH and/or prostatitis in the majority of cases in Arabic populations.

Western studies have demonstrated that men subjected to prostatic biopsy on a screening basis with a serum PSA value $<4 \mathrm{ng} / \mathrm{mL}$ had a prostate cancer incidence ranging from 15 to $28 \%$. Our study demonstrates that an increase in the PSA level at the second visit, although remaining below $4 \mathrm{ng} / \mathrm{mL}$, can improve cancer prediction by increasing the positive detection rate by biopsy to $34 \%$. In contrast, Arabic studies have demonstrated cancer detection rates ranging from 1.8 to $10.6 \%$, compared to the $13 \%$ observed in the KSUH group, and have considered rising PSA levels to indicate cases that would benefit from biopsy. In the KSUH cohort, the incidence of cancer detection among men with PSA levels ranging from 4 to $10 \mathrm{ng} / \mathrm{mL}$ was zero, and the actual cancer incidence of men in the KSUH group with a PSA level $<10 \mathrm{ng} / \mathrm{mL}$ serum was $6.6 \%$, which is low, considering the recommendation for prostatic biopsy of Arabic men with PSA levels $<10 \mathrm{ng} / \mathrm{mL}$.

Although the PSAd was significantly higher in the cancer group and a PSAd value of $>0.15$ was significantly associated with a higher cancer detection incidence in the MUHC and KSUH cohorts, this characteristic did not appear to be a clinically valuable factor for inclusion in prostatic biopsy decision making because the median PSAd values were not significantly different between men with or without cancer, after classifying patients according to PSA values $<10 \mathrm{ng} / \mathrm{mL}$. Cookson et al. (33) also found that the PSAd value did not discriminate between patients with positive and negative biopsies and a PSA $<10 \mathrm{ng} / \mathrm{mL}$.

By correlating the prostate volume with the PSA level in the MUHC and KSUH cohorts, small prostate volumes were significantly associated with a higher PSA level in the MUHC group, which could be explained by the higher prostate cancer incidence found in that group, in addition to the lower incidence of BPH or cancer in the KSUH group. Although the prostate cancer incidence was consistent and significantly lower in the KSUH group, the insignificant difference in PSA levels in comparison to 
the MUHC group could be explained by the higher prevalence of $\mathrm{BPH}$ in that group, and $\mathrm{BPH}$ is also present in the majority of cases associated with high PSA levels in Arabic populations.

Taken together, our data demonstrate that there is a significantly lower prevalence of prostate cancer in Arabic populations compared to Western populations, although no current theory is able to explain this lower prevalence. PSA is a valuable marker for the recommendation to perform a prostate biopsy, although it is recommended that its use for recommending a biopsy be adjusted based on the geographic and/or ethnic differences in the populations being investigated. In addition, it is possible that a different set of PSA cut-offs may be required in the

\section{References}

1. Boyle P, Severi G, Giles GG. The epidemiology of prostate cancer. Urol Clin North Am 2003; 30: 209-217, doi: 10.1016/ S0094-0143(02)00181-7.

2. Muir CS, Nectoux J, Staszewski J. The epidemiology of prostatic cancer. Geographical distribution and timetrends. Acta Oncol 1991; 30: 133-140, doi: 10.3109/ 02841869109092336.

3. Parkin DM, Whelan SL, Ferlay J, Raymond L, Young $\mathrm{J}$ (Editors). Cancer incidence in five continents. Lyons: IARC Scientific Publications, No. 143; 1997, doi: 10.1002/ (SICI)1097-0258(20000515)19:9<1261::AID-SIM386>3.0.CO; 2-L.

4. Hanash KA, Al-Othaimeen A, Kattan S, Lindstedt E, AlZahrani $\mathrm{H}$, Merdad T, et al. Prostatic carcinoma: a nutritional disease? Conflicting data from the Kingdom of Saudi Arabia. J Urol 2000; 164: 1570-1572, doi: 10.1016/S00225347(05)67030-9.

5. Kehinde EO. Prostate cancer in the Middle East: perspective Oman. In: Belldegrun A, Kirby RS, Oliver RTD (Editors), New perspectives in prostate cancer. Oxford: ISIS Medical Media; 1998. p 383-390.

6. Memon A, Al-Muhanna AN. Annual cancer incidence in Kuwaitis 1992-1993. Vol. VIII, No. 143. In: Parkin DM, Whelan SL, Ferlay J, et al. (Editors), Cancer incidence in five continents. Lyons: IARC Scientific Publications; 1997. p 410-417.

7. Morris BJ. Why circumcision is a biomedical imperative for the $21^{\text {st }}$ century. Bioessays 2007; 29: 1147-1158, doi: 10.1002/bies.20654.

8. Dillner J, Knekt P, Boman J, Lehtinen M, Af Geijersstam V Af, Sapp M, et al. Sero-epidemiological association between human-papillomavirus infection and risk of prostate cancer. Int J Cancer 1998; 75: 564-567, doi: 10.1002/(SICI)10970215(19980209)75:4<564::AID-IJC12>3.0.CO;2-9.

9. Castellsague X, Bosch FX, Munoz N, Meijer CJ, Shah KV, de Sanjose $S$, et al. Male circumcision, penile human papillomavirus infection, and cervical cancer in female partners. N Engl J Med 2002; 346: 1105-1112, doi: 10.1056/ NEJMoa011688.

10. Al Moustafa AE. Involvement of human papillomavirus infections in prostate cancer progression. Med Hypotheses 2008; 71: 209-211, doi: 10.1016/j.mehy.2008.03.036.
Arabic population as opposed to the current standards in use in North America; however, determining this cut-off will require further prospective analyses to better define optimal PSA values for the Arab world.

\section{Acknowledgments}

The authors extend their appreciation to the Deanship of Scientific Research at King Saud University for funding this work through research group No. RGP-VPP-078. Research supported by Princess Al-Johara Al-Ibrahim Center for Cancer Research, King Saud University Hospital (King Khaled Hospital), King Saud University, Riyadh, Kingdom of Saudi Arabia.
11. Apt A. Circumcision and prostatic cancer. Acta Med Scand 1965; 178: 493-504, doi: 10.1111/j.0954-6820.1965.tb04294.x.

12. Ewings $P$, Bowie $C$. A case-control study of cancer of the prostate in Somerset and east Devon. Br J Cancer 1996; 74: 661-666, doi: 10.1038/bjc.1996.418.

13. International Agency for Research on Cancer (IARC). CANCER Mondial Statistical Information System (http://www-dep.iarc.fr/).

14. Shimizu H, Ross RK, Bernstein L, Yatani R, Henderson BE, Mack TM. Cancers of the prostate and breast among Japanese and white immigrants in Los Angeles County. Br J Cancer 1991; 63: 963-966, doi: 10.1038/bjc.1991.210.

15. Kamel NM, Tayel ES, El Abbady AA, Khashab SS. Risk factors of cancer prostate. A case control study. J Egypt Public Health Assoc 2006; 81: 143-163.

16. Ma RW, Chapman K. A systematic review of the effect of diet in prostate cancer prevention and treatment. J Hum Nutr Diet 2009; 22: 187-199, doi: 10.1111/j.1365-277X.2009.00946.x.

17. Schwartz KL, Kulwicki A, Weiss LK, Fakhouri H, Sakr W, $\mathrm{Kau}$ G, et al. Cancer among Arab Americans in the metropolitan Detroit area. Ethn Dis 2004; 14: 141-146.

18. Kehinde EO, Akanji AO, Al-Hunayan A, Memon A, Luqmani $Y$, Al-Awadi $K A$, et al. Do differences in age specific androgenic steroid hormone levels account for differing prostate cancer rates between Arabs and Caucasians? Int J Urol 2006; 13: 354-361, doi: 10.1111/j.1442-2042.2006.01305.x.

19. Al Attia HM, Jaysundaram K, Saraj F. Lack of biochemical hypogonadism in elderly Arab males with low bone mineral density disease. Rheumatol Int 2010; 30: 365-367, doi: 10.1007/s00296-009-0970-z.

20. Battikhi MN. Age-specific reference ranges for prostatespecific antigen (PSA) in Jordanian patients. Prostate Cancer Prostatic Dis 2003; 6: 256-260, doi: 10.1038/ sj.pcan. 4500656 .

21. Catalona WJ, Richie JP, Ahmann FR, Hudson MA, Scardino $\mathrm{PT}$, Flanigan RC, et al. Comparison of digital rectal examination and serum prostate specific antigen in the early detection of prostate cancer: results of a multicenter clinical trial of 6,630 men. J Urol 1994; 151: 1283-1290.

22. Gann PH, Hennekens $\mathrm{CH}, \mathrm{Ma}$ J, Longcope C, Stampfer MJ. Prospective study of sex hormone levels and risk of prostate cancer. J Natl Cancer Inst 1996; 88: 1118-1126, doi: 10.1093/jnci/88.16.1118. 
23. $\mathrm{Ku} \mathrm{JH}$, Ahn JO, Lee $\mathrm{CH}$, Lee NK, Park YH, Byun SS, et al. Distribution of serum prostate-specific antigen in healthy Korean men: influence of ethnicity. Urology 2002; 60: 475479, doi: 10.1016/S0090-4295(02)01807-1.

24. Schroder FH, Wildhagen MF. Screening for prostate cancer: evidence and perspectives. BJU Int 2001; 88: 811-817, doi: 10.1046/j.1464-4096.2001.02449.x.

25. Benson MC, Whang IS, Pantuck A, Ring K, Kaplan SA, Olsson CA, et al. Prostate specific antigen density: a means of distinguishing benign prostatic hypertrophy and prostate cancer. J Urol 1992; 147: 815-816.

26. Cao XL, Gao JP, Han G, Tang J, Hong BF. [Relationship between screening by stratifying cases into groups on prostate specific antigen level and the positive rate of transrectal ultrasound guided systematic sextant prostate biopsy]. Zhonghua Wai Ke Za Zhi 2006; 44: 372-375.

27. Zheng $X Y$, Xie LP, Wang YY, Ding $W$, Yang K, Shen HF, et al. The use of prostate specific antigen (PSA) density in detecting prostate cancer in Chinese men with PSA levels of 4-10 ng/mL. J Cancer Res Clin Oncol 2008; 134: 12071210, doi: 10.1007/s00432-008-0400-8.

28. Muezzinoglu T, Lekili M, Eser E, Uyanik BS, Buyuksu C. Population standards of prostate specific antigen values in men over 40: community based study in Turkey. Int Urol
Nephrol 2005; 37: 299-304, doi: 10.1007/s11255-004-7976-y.

29. Hosseini SY, Moharramzadeh M, Ghadian AR, Hooshyar H Lashay AR, Safarinejad MR. Population-based screening for prostate cancer by measuring total serum prostatespecific antigen in Iran. Int $J$ Urol 2007; 14: 406-411, doi: 10.1111/j.1442-2042.2006.01729.x.

30. Kamal BA, Ali GA, Taha SA. Prostate specific antigen reference ranges in Saudi men. Saudi Med J 2003; 24 665-668.

31. Anim JT, Kehinde EO, Sheikh MA, Prasad A, Mojiminiyi OA, Ali Y, et al. Serum prostate-specific antigen levels in Middle Eastern men with subclinical prostatitis. Med Princ Pract 2007; 16: 53-58, doi: 10.1159/000096141.

32. Kehinde EO, Mojiminiyi OA, Sheikh M, Al-Awadi KA, Daar AS, Al-Hunayan A, et al. Age-specific reference levels of serum prostate-specific antigen and prostate volume in healthy Arab men. BJU Int 2005; 96: 308-312, doi: 10.1111/ j.1464-410X.2005.05620.x.

33. Cookson MS, Floyd MK, Ball TP Jr, Miller EK, Sarosdy MF The lack of predictive value of prostate specific antigen density in the detection of prostate cancer in patients with normal rectal examinations and intermediate prostate specific antigen levels. J Urol 1995; 154: 1070-1073, doi: 10.1016/S0022-5347(01)66979-9. 